\title{
EXPERIMENTAL INVESTIGATION ON RHEOLOGICAL PROPERTIES OF WATER BASED NOVEL TERNARY HYBRID NANOFLUIDS
}

\author{
Jalal Mohammed Zayan ${ }^{1}$, Abdul Khaliq Rasheed ${ }^{2 *}$, Akbar John ${ }^{3}$, Mohammed Khalid $^{4}$, Ahmad Faris \\ Ismail $^{1}$
}

${ }^{1}$ Department of Mechanical Engineering; ${ }^{3}$ Institute of Oceanography and Maritime Studies (INOCEM), Kuantan; International Islamic University Malaysia, 53100 Malaysia

${ }^{2}$ Department of New Energy Science and Engineering, School of Energy and Chemical Engineering. Xiamen University Malaysia. Jalan Sunsuria, Bandar Sunsuria, 43900 Sepang, Selangor. Malaysia

${ }^{4}$ Graphene \& Advanced 2D Materials Research Group (GAMRG), School of Engineering and Technology, Sunway University, No. 5, Jalan Universiti, Bandar Sunway, 47500 Petaling Jaya, Selangor, Malaysia.

*Corresponding author: rakhaliq47@yahoo.com

\begin{abstract}
:
This study presents the rheological characterization of deionised water dispersed with two different

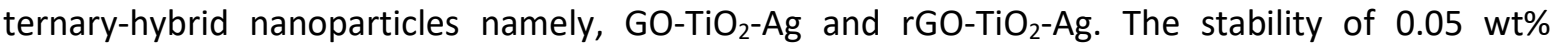
nanofluid samples are serially diluted by 10 fold in 5 levels is determined using zeta potential measurements. The non-linear viscoelastic measurements at temperatures ranging from $25^{\circ} \mathrm{C}$ to $50^{\circ} \mathrm{C}$ reveal that the graphene based ternary hybrid nanofluids exhibit Newtonian behaviour at higher concentrations. However, it displays shear thinning or pseudo-plastic fluid characteristics at lower concentration, suggesting a potential influence of nanoparticle aggregation on the viscosity. The experimental results are found to be in good agreement with the existing water based viscosity models. In addition, the effect due to shear stress, angular sweep, frequency sweep and damping factor ratio is also plotted.
\end{abstract}

Keywords: Ternary Hybrid nanoparticles; Hybrid nanofluids; shear rate; pseudo-plastic behaviour

\section{Introduction}

Colloidal suspensions of nanoparticles in base fluids are called nanofluids. Nanoparticles are typically dispersed in base fluids such as water, ethylene glycol, oils and synthetic fluids such as liquid paraffin oil and polyester. Gold, silver, titanium, aluminium, iron oxide etc. are commonly used metallic nanoparticles. The carbon-based nanoparticles used are diamonds, graphene, CNT, fullerenes, etc. Some other non-carbon, non-metallic nanoparticles include sodium, ceramic, carbides etc. [1]. Nanofluids are novel fluids which enhances the heat transfer or thermal conductivity of base fluids. They are adapted in many major industrial and biomedical applications where rapid heating and cooling are critical such as engines, power plants, pharmaceutical processes, vehicle thermal management, to name a few [2]. These industries needs fluids with higher thermal conductivity and better rheological properties as their working fluid. Thermal conductivity enhancement is the ability of the matter to transmit or dissipate greater magnitude of heat at a faster rate. This improved heat transfer fluid decreases time and energy consumption. The rheological properties of materials and fluids is the study of its viscosity or the resistance to deformation. Rheology is a correlation of stress and strains that can be used to study and understand the basic behaviour and characteristics of fluids which are essential for deriving viscosity models. Dispersing nanoparticles in base fluids increases the thermal conductivity as well as alters the rheological behaviour and other structural properties 
of the fluids. The detailed rheological study of nanofluids will allow us to determine whether the fluid is Newtonian or non-Newtonian, the structural evolution of solid-liquid dispersion, pumping power and also to interpret and quantify the mechanics of the solid-fluid interaction under different temperature and stress conditions. Dispersing solid nano-sized particles in standard base fluids will also induce a decrease in the system pressure. An example of this is the shear thinning of nanofluids due to the different shapes of the particles contributing to the agglomeration of the particles in the fluids, thus affecting their efficiency. Other factors influencing the rheological properties include, the $\mathrm{pH}$ of the nanofluid, the volume fraction of the nanoparticle, the shearing rate of the liquid layer of the sample, the selection of the base fluid, the size and shape of the nanoparticle. The stability of the nanoparticle in the fluid and its duration without sedimentation, etc., also influence the viscosity of the nanofluids. In view of all these considerations, it is important to study the effect of dispersing nanoparticles in base fluids on the structure of fluids and their rheological behaviour, change in their chemical structure under different stress and temperature conditions [3]. Studies has investigated the effects of nanoparticles and also the type of nanoparticles used such as graphene [4], gold[5], aluminium, hybrid nanofluids [3] and other nanoparticles based nanofluids and their applications [6]. Few research have showed an increase in thermal conductivity, which has enhanced the efficiency of their applications. One such research using nanoparticles has shown to accelerate thermal conductivity of polymerase chain reaction (PCR) by significantly reduce the number of cycles with the addition of graphene nanoflakes [7] and titanium nanoparticles [8]. Few other studies have observed that with the addition of nanoparticles, the applications yielded better outcomes in fields such as medical [5], nuclear reactors [9], oil recovery [10], etc.

Nanofluids containing more than one type of single material nanoparticle are referred to as hybrid nanofluids are extensively studied by many researchers in the current decade. Hybrid nanoparticles are a combination of two or more nanoparticles synthesised or decorated on top of each other and their dispersion into base fluids is known as hybrid nanofluids. They have a special attribute of improved thermal conductivity as well as tailor-made rheological properties that make them desirable to a wide variety of applications. These properties of nanofluids draw a lot of researchers to explore the applications of hybrid nanofluids in diverse fields of application [11]. Numerous hybrid nanofluids have been studied in the literature which include dispersion of hybrid nanoparticles in metallic form such as silver-gold hybrid [12] or a mixture of carbon-metallic nanoparticles such as graphene -titanium di oxide [13] etc. to mention a couple of them. Each of these hybrid nanoparticles has distinct characteristics and behaviours. Numerous studies and reviews has published about hybrid nanofluid preparation methods [14], characterization [15] , thermal conductivity enhancements [16] , thermal conductivity models [17], thermal conductivity mechanisms [18], particle size and shape impact on thermal conductivity [19], rheological effects on the base fluids due to the dispersion of hybrid nanoparticles [3], rheological behaviour [20], viscosity [21], viscosity models [22] effect of particle size and shape on the viscosity [23] and stability [1]. Hybrid nanofluid studies have only recently gained momentum [6]. Bi-hybrid nanoparticles have been used in various studies such as CuO-MWCNT[24], $\mathrm{Al}_{2} \mathrm{O}_{3}-\mathrm{TiO}_{2}$ [25], $\mathrm{SiO}_{2}-\mathrm{MWCNT}$ [26], MWCNTGNPs [27], to name a few. However, very few studies have been done to date on the rheological behaviour of tri-hybrid/ternary hybrid nanoparticles with different concentrations and their sweep characteristics, such as amplitude sweep and frequency sweep focused on storage and loss modulli. Furthermore, relatively few studies have observed the rheological effects of dispersing minute or very low concentrations of nanoparticles on base fluids ( $<1 \% \mathrm{wt}$ ) which can be categorized as dilute [28]. The other aspect to consider in this analysis is the lack of proper rheological observations by studies on tri-hybrid or ternary hybrid nanoparticles dispersed in DI water. 
In this study, three distinct nanoparticles, such as graphene, titanium oxide and silver, are decorated on each other forming a novel tri-hybrid or ternary hybrid nanoparticles (THNp). Ternary hybrid nanofluids were produced by dispersing the two forms of graphene-based hybrid nanoparticles in the base fluid. Nanofluids are then diluted in sequence at varying concentrations. Characterization of the nanoparticles was performed using FTIR, SEM, XRD and Raman spectroscopy. Zeta potential measurements were performed to verify the stability of the two ternary hybrid nanofluids. Rheological experiments were carried out at different temperature periods. Viscosity Vs shear rate and temperature was measured along with other rheological parameters, such as Amplitude Sweep and Frequency Sweep with Loss and Storage Units at different temperatures.

\section{Materials and methodology}

\subsection{Synthesis of ternary hybrid nanoparticles}

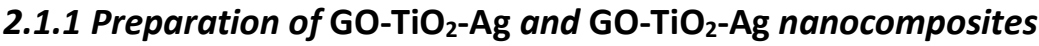

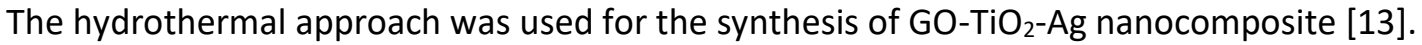
Graphene oxide (GO) of approximately $0.25 \mathrm{~g}$ was dispersed in $250 \mathrm{ml}$ of deionized water by ultrasonic stirring for approximately 2 hours. Separately, $10 \mathrm{ml}$ of Titanium isopropoxide (TTIP) and silver was combined with $10 \mathrm{ml}$ of isopropyl alcohol and this solution was added to $50 \mathrm{ml}$ of GO suspension. After that $10 \mathrm{ml}$ of $0.2 \mathrm{M} \mathrm{AgNO}_{3}$ was added drop-wise to the solution. The solution was then mixed and stirred for about 30 minutes and the $\mathrm{pH}$ was altered to 1.1 while the stirring was continued for about two hours in order to produce a uniform homogeneous solution. This homogeneous solution is heated at $160^{\circ} \mathrm{C}$ for 24 hours in a Teflon-lined stainless steel autoclave. The substance was vigorously sprayed with ethanol and then washed with water to remove all traces and unreacted ions. The solution is then purified and dried to $80^{\circ} \mathrm{C}$ to obtain $\mathrm{GO}-\mathrm{TiO}_{2}-\mathrm{Ag}$ nanocomposites. Similar

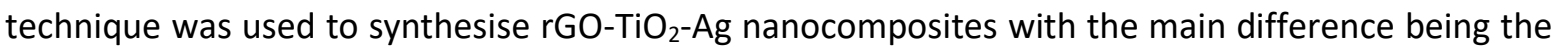
addition of ammonia and hydrazine. These compounds have been employed to reduce oxygen molecules from GO sheets and their functional groups. Nanofluids were prepared using nanoparticles with different concentration ratios in deionized water. The Bath Sonicator was used to sound the nanofluids for around 4 hours.

\subsection{Material Characterization}

Characterization of hybrid nanoparticles was performed using the Fourier Transform Infrared Spectroscopy (FT-IR) spectra. The Bruker IFS66/S infrared spectrometer was used to measure with a resolution of $\pm 4 \mathrm{~cm}-1$ and a scan number of 16 and in the range of $4000-400 \mathrm{~cm}-1$. Laser Raman spectroscopy (LRS) was conducted on nanomaterials at room temperature in the $200-3000 \mathrm{~cm}-1$ range and on UV excitation in the $325 \mathrm{~nm}$ range using He-Ne laser (model RENISHAW in via Raman Microscope). The surface topography was measured by Field Emission Scanning Electron Microscopy (FE-SEM) at $30 \mathrm{kV}$. Powder X-ray diffraction (XRD) patterns were used on a PAN analytical, X'Pert High Score diffractometer with primary monochromatic high-intensity CuK5-007radiation (5-007 = $0.15406 \mathrm{~nm}$ ).

\subsection{Preparation of nanofluids}

The preparation of nanofluids has an important role in obtaining the desired stability characteristics. Improving uniform dispersal and achieving the desired properties allows a nanofluid to be durable without sedimentation. Sartorius Entris ${ }^{\circledR}$ designed electronic balance was used to measure THNp 
( $r \mathrm{GO}-\mathrm{TiO}_{2}-\mathrm{Ag}$ and $\left.\mathrm{GO}-\mathrm{TiO}_{2}-\mathrm{Ag}\right)$ and was then dispersed in Double distilled and deionised water. 2.5 $\mathrm{mg}$ THNp was dispersed in $50 \mathrm{ml}$ of deionized water at a concentration of $0.05 \mathrm{Wt} \%$. This concentration can be called semi-dilute (i.e. $~ 0.001<\varphi<\sim 0.05$ ). Initially, the nanofluids were sonicated using an ultrasonic probe sonication for 10 minutes and then accompanied by a water bath sonication for around 4 hours to attain a homogenous nanofluid solution without sedimentation. The stock solution was then serially diluted at around 5 levels of $0.05 \mathrm{wt} \%$ (from semi-dilute to dilute concentrations of nanofluids).

\subsection{Stability of ternary hybrid nanofluids}

Anton Paar Electrokinetic Analyzer SurPASS 3 was used to evaluate the zeta potential of the prepared nanofluids. It is a measure of stability and surface load at a solid-liquid interface. The electrostatic repulsion forces and the zeta potential are directly propotional. The electrostatic repulsion force is supposed to be stronger than the precipitation forces of attraction. For the stabilisation of nanofluids with solid dispersion, the optimal absolute zeta potential should be approximately $30 \mathrm{mV}$. From the zeta potential figure below (fig 1 ), it can be seen that the peak measured for ternary hybrid nanofluids is roughly $25 \mathrm{mV}$ to $5 \mathrm{mV}$, which are within a stable limit. Zeta potential of less than $20 \mathrm{mV}$ is known to be unstable dispersion.

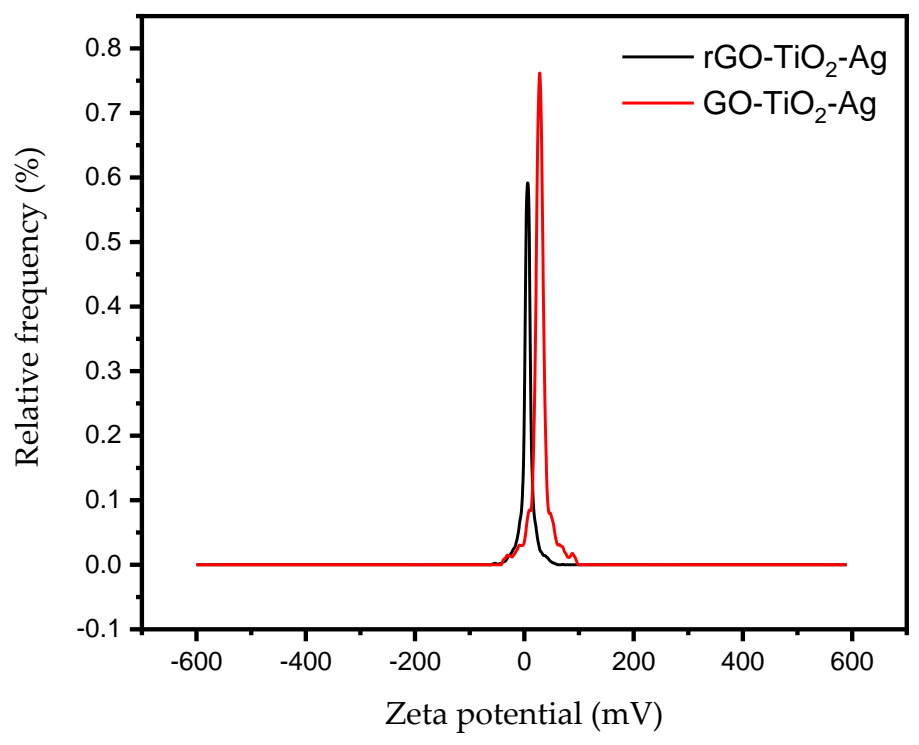

Figure 1: Zeta potential of ternary hybrid nanofluids

\subsection{Viscosity measurements}

Anton Paar's (GmbH, Austria) MCR302 modular compact rheometer was used to evaluate the dynamic viscosity of hybrid nanofluids. The Peltier balancing cell C-PTD200 is used by the rheometer to maintain the temperature of the sample. Measurements of viscosity, shear rate and shear stress were conducted using a 1-100 1/s spindle. CC45 DIN at temperatures ranging from 25 to $50^{\circ} \mathrm{C}$ with increments of $5^{\circ} \mathrm{C}$. The ternary hybrid nanofluids were loaded within the sample chamber of the rheometer. The double gap spindle was submerged and rotated against the ternary hybrid nanofluid. The drag force against the spindle rotation is calculated by the amplitude of the deflection of the calibrated spring. Shear strain, shear stress and nanofluid viscosity are then measured at ambient temperature. The results of the measured variables are reported by the data logger of the equipment. The rheometer is very precise with an accuracy that is guaranteed to be within $\pm 1 \%$. The 
reproducibility of the spindle speed of the rhoemeter is within \pm 0.2 . Ternary hybrid nanofluids have opposing viscous effect against spindle rotation. Measurements of viscosity, shear stress and shear strains for ternary hybrid nanofluids are made at different temperatures ranging from $25^{\circ} \mathrm{C}$ to $50^{\circ} \mathrm{C}$ with increments of $5^{\circ} \mathrm{C}$ for ternary hybrid nanofluids. The results demonstrate that the viscosity of hybrid nanofluids is almost linear at measured temperatures, suggesting Newtonian fluid. It can also be shown that ternary nanofluids have slightly higher viscosities than base fluids [33].

\section{Results and discussion}

In general, the rheological behaviour of nanofluids is of remarkable importance in a wide range of applications [30]. There is a proportional relationship between different variables, such as viscosity, shear rate, pumping power and pressure decrease, as well as convective heat transfer in fluids. The change in viscosity is primarily due to two significant features, such as temperature change and the increase/decrease in nanoparticle concentrations in the nanofluids. Other factor that increase viscosity is the interaction between $\mathrm{k}$ and the viscosity of nanofluids. Many reports have also shown that viscosity is also affected by the element k. Few studies have also shown that the viscosity is also depending on the size of the nanomaterials with a variation of more than 5\% [31]. The viscosity of nanofluids varies with the material type of nanoparticles and their behaviour, whether metallic or non-metallic. Another important aspect is the shape of the particle.

\subsection{Viscosity Vs Shear rate}

\section{a. Effect of ternary hybrid nanoparticle type on viscosity}

Viscosity measurements were conducted for the two ternary hybrid nanoparticles prepared with five different concentrations of nanofluids. Of the five samples measured, the concentration of $0.0005 \mathrm{wt}$ $\%$ (sample E (5x10-5)) wt \% was chosen to evaluate the effect of the shear rate on viscosity with respect to temperature. Figure 2 shows that the viscosity of nanofluids is decreased by increasing the shear rate at various temperatures. Ternary hybrid nanofluids behave like Newtonian fluids at lower temperatures. At higher temperatures and lower shearing rates, viscosity decreases, as reported in a number of studies, suggesting shear thinning behaviour [20]. Viscosity of the ternary hybrid nanofluids are very high at $40^{\circ} \mathrm{C}$ and $50^{\circ} \mathrm{C}$. The potential explanation for this phenomenon is that the nanoparticles in fluid aggregates with other particles similar to nano-cluster formation due to Van der Waal forces of attraction between nanoparticles and higher resistance to flow as the shear rate is lower at higher temperatures. Agglomeration of nanoparticles at higher temperatures creates internal shear stress between particle-fluid interface interactions, resulting in increase of viscosity in the hybrid nanofluids. Binding energy can be another phenomenon occurring at higher temperatures leading to agglomeration or the formation of micro clusters in nanofluids, which increases viscosity at higher temperatures [32]. The hydration layer formation on the nanoparticle-fluid interface increases the cohesion potential between the solid and liquid layers that are typically responsible for transferring or dissipating heat, which may be acting as solid at a nanoscale level. This interaction of solid-liquid layers can be higher at higher temperatures as the liquid layer needs to transfer or dissipate higher amounts of heat energy. This behaviour of liquid layers acting as solid particles leads to an increase in viscosity [32]. Nanoparticles form clusters due to higher attractive forces at higher temperatures contributing to the increase in viscosity [3]. Then as the shear rate increases, the attractive forces between the nanoparticles are reduced and the particles scattered, leading to a reduction in viscosity, which can be termed shear thinning behaviour. Shear thinning can be associated with pseudo-plastic behaviour. This is the result of small structural improvements in fluid with microscale fluid geometries to allow the shearing of fluids themselves. Phase separation is 
another phenomenon that contributes to shear thinning in nanofluids. Numerous studies have reported the measured the rheological properties of different nanofluids. Studies also documented the effects of the presence of nanoparticles on the rheological properties of the base fluid. Rheological studies were carried out to determine whether the decrease in pressure and the structure of nanoparticles can help predict the thermal conductivity of nanofluids [20]. Numerous theoretical models for different concentrations have also been presented to date, along with experimental observations of nanofluids [23]. Much of the experiments were performed on the basis of single material nanoparticles, and theoretical models are also derived for the same [33]. Rheological investigations found that viscosity improved against water with nanoparticles[28]. Single component nanoparticles of aluminium oxide, silicon dioxide and titanium dioxide were used at a concentration of $4.3 \%$. Wang et al was observed pseudo-plastic behaviour in the nanofluid with the addition of graphite to oil. Viscosity was improved along with a visco-elastic rise of approximately $1.36 \mathrm{vol} \%$ [34]. Newtonian behaviour was reported in the use of hybrid nanofluid with Cu-Zn (1:1) alloy with vegetable oil exhibiting linear relationship between shear stress and shear rate with lower viscosity[35].

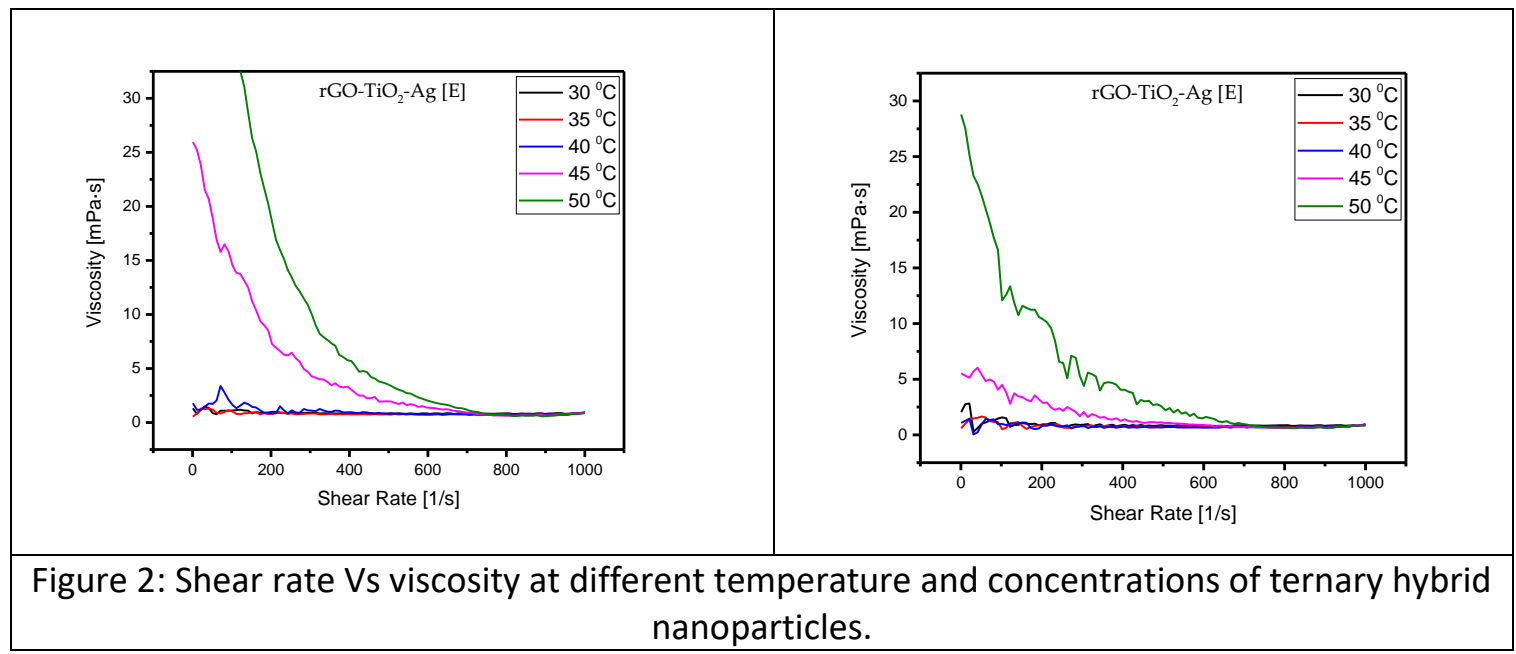

\section{b. Effect of ternary hybrid nanoparticle type on concentration}

The measurement plots in figure 3 shows the variation of viscosity with the change in the concentration of nanofluids. The variables $A$ to $E$ represents five levels of serial dilution of the nanofluids with $A$ as the highest concentration of $5 \times 10^{-1}$ and $E$ as the lowest concentration of $5 \times 10^{-}$ 5 . The two ternary hybrid nanofluids are inversely proportional in terms of their increase in viscosity. The viscosity of the $\mathrm{GO}$ based ternary hybrid nanofluid increases with the decrease in concentration whereas it is otherwise in the rGO based ternary hybrid nanofluid in which the viscosity decreases with the decrease in concentration in various measured temperatures. It can be seen from the plots of both GO and rGO based THNPs, viscosity of individual concentration increases gradually with the increase in temperature. Generally, the viscosity of the water based nanofluids decrease with lower concentrations. This was observed in the rGO based nanofluids. The GO based ternary hybrid nanofluids behaves otherwise. From both the plots it can be seen that at $35^{\circ} \mathrm{C}$ the nanofluids has a spike in the viscosity, which can be considered as an optimum operating temperature. The GO based ternary hybrid nanofluid, the concentration $D\left(5 \times 10^{-4}\right)$ has an increase of viscosity of about $50 \%$ at almost all the temperatures measured. Similar hike in viscosity can be seen in the concentration $\mathrm{C}$ $\left(5 \times 10^{-3}\right)$ in the rGO based ternary hybrid nanofluids. It can also be noted that $\mathrm{GO}$ based ternary hybrid nanofluid has significantly higher viscosity at all concentrations and temperatures compared to $\mathrm{rGO}$ based ternary hybrid nanofluid. The increase in viscosity of the GO based nanofluids may be 
due to various factors. A slight variation of the concentration of the nanofluids tends to increase or decrease the rheological property of the nanofluids. Almost all researches on nanofluids has reported the same. Substantial efforts have been applied on research of concentrations or volume fractions of nanoparticles in the nanofluids. There is a strong relationship between the increase in concentration of nanoparticles and the increase in viscosity [35]. Few reports have studied the Newtonian behaviour of water based metallic nanofluids where the viscosity increased with the increase of concentration of nanoparticle on the fluid [28] . The viscosity increased can be as low as 4 to $15 \%$ or it can be as high as $50 \%$ [21]. It can be seen that viscosity is detrimental to the increase of thermal conductivity in the nanofluids but it can't be generalised that the increase of nanoparticle concentration will lead to increase in viscosity. The figure 3 below shows the viscosity measurements of the two ternary hybrid nanoparticles.

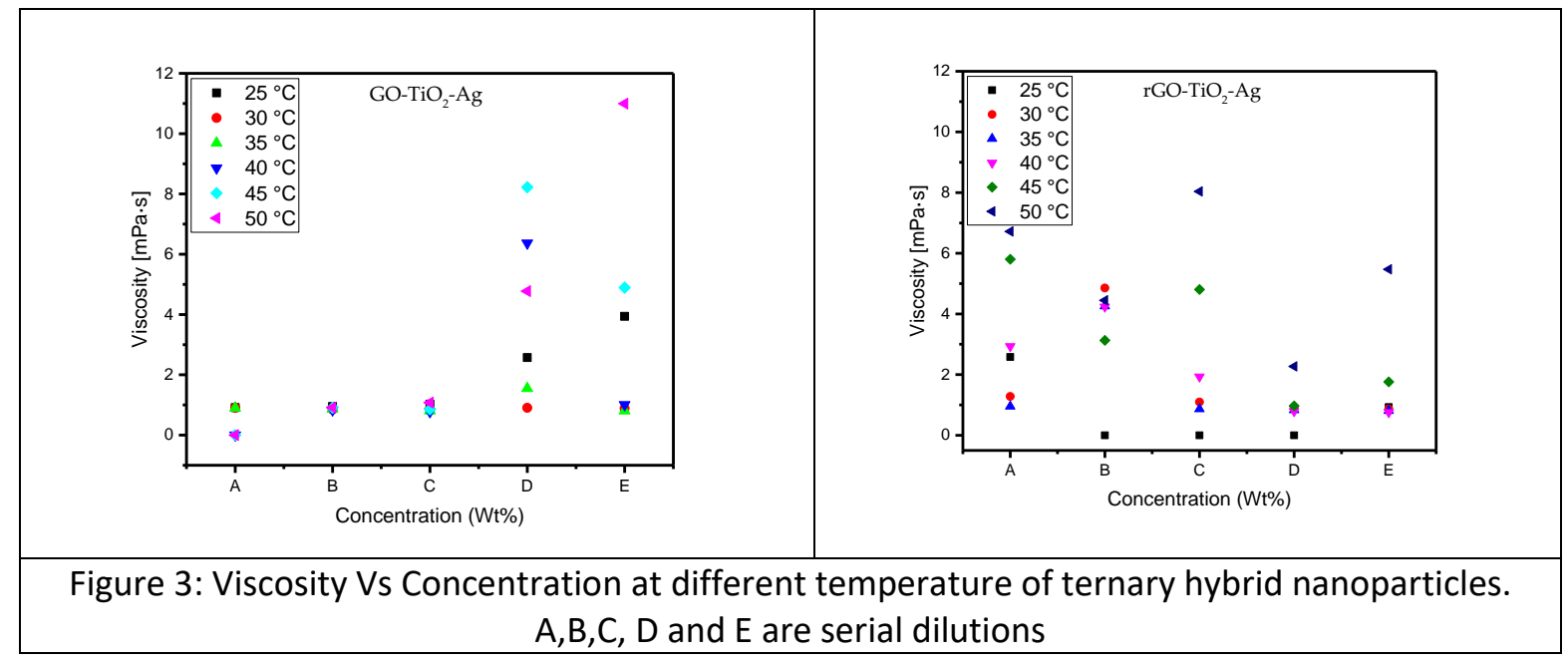

\section{c. Effect of ternary hybrid nanoparticle type on temperature}

The viscosity of water, EG, and oil based nanofluids decreases with the increase in temperature of the fluid is a known phenomenon. The rate of decrease in viscosity due to an increase in temperature depends in the fluid's intrinsic property or the intermolecular bond strength. Increasing the temperature of the fluid basically is supplying the molecules in the fluids with higher energy. In case of nanofluids, which has additional particles, this increase of temperature leads to increased heating and heat transfer leading to faster weakening of the intermolecular forces which decreases the viscosity of the fluid. The intermolecular interactions between the water-nanoparticle becomes weaker with the increase in the temperature of the fluid leading to decrease of viscosity in the ternary hybrid nanofluid. The strong van der Waals forces acts on the particles in lower temperatures. Once the temperature is increased, the forces weaken leading to decrease in viscosity[36]. The figure 4 depicts the averaged plot of viscosity verses temperature in terms of concentration of $\mathrm{GO}$ and $\mathrm{rGO}$ based ternary hybrid nanofluids. It can be seen that the viscosity is almost similar except for a slight variation with the lower concentration fluid exhibit slightly higher viscosity at lower temperatures [37]. The rGO based ternary hybrid nanofluids shows a similar trend in which the viscosity decreases with the increase in temperature of the fluid for all concentrations. The concentration B shows a higher viscosity than the other concentration while the lowest concentration have a lower viscosity 


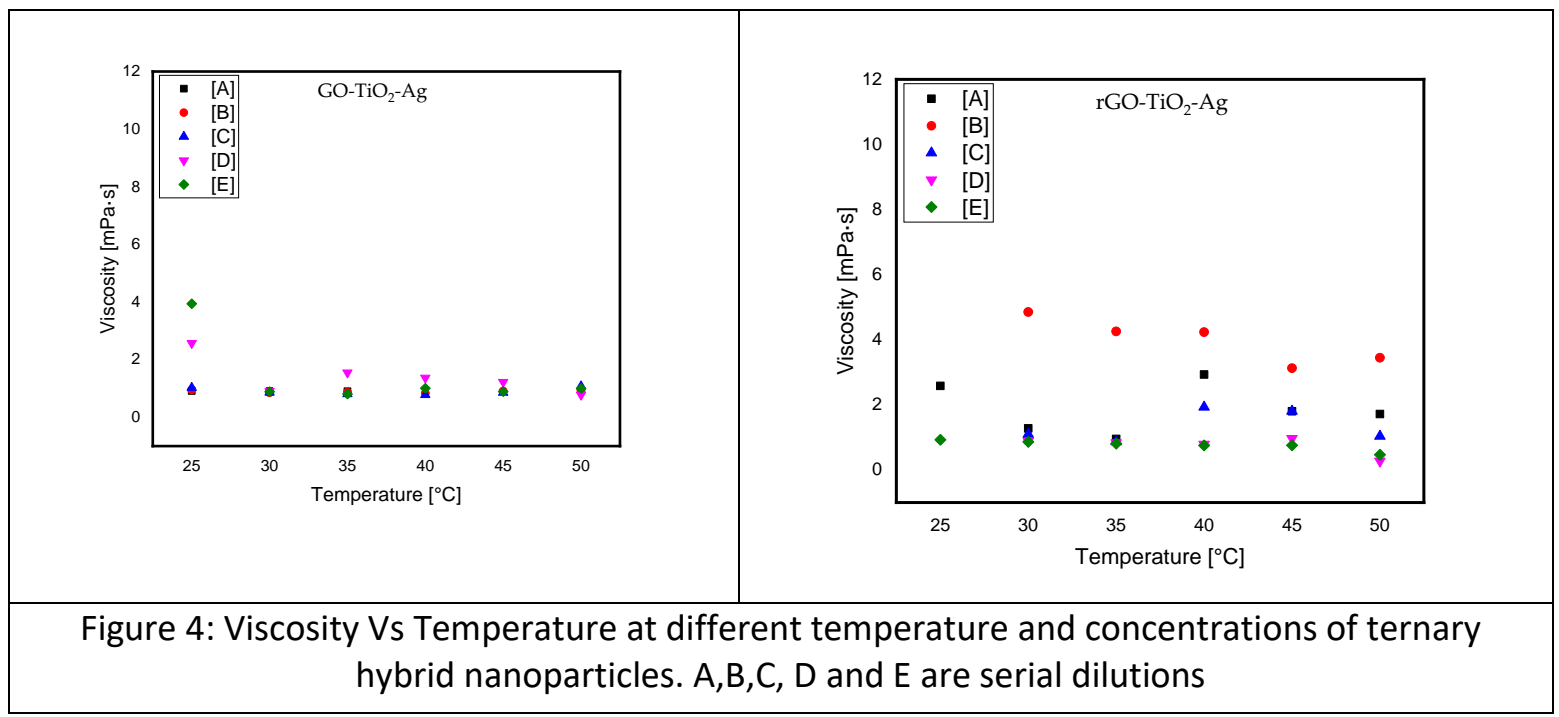

It shows that the concentration plays a vital role in the change of viscosity with the change in temperature. The viscosity increases or decreases with the change in temperature. The addition of heat changes the nanoparticles in the fluid from surface force attraction to interatomic bonding [38]. The change is more noticeable when between the different concentration samples of the nanofluids. This may be due to the agglomeration of nanoparticles in higher temperatures[23]. Similar results were observed by most researchers who studied the effect of temperature on the viscosity of the nanofluids based on different levels of concentration. Shah. $\mathrm{S}$ et al, in his study on $\mathrm{rGO}$ based ethylene glycol nanofluids reported a viscosity decrease of $56.4 \%$ and $73.9 \%$ at $50{ }^{\circ} \mathrm{C}$ and $70{ }^{\circ} \mathrm{C}$ respectively [39]. Hu, Xichen et al has reported an astronomic viscosity decrease of about $593 \%$ at $50^{\circ} \mathrm{C}$ for their study graphite/engine oil nanofluids [37]. Few researchers reported the effect of temperature on the viscosity of hybrid nanofluids, Esfe and Rostamian reported that there was a $171 \%$ decrease of viscosity form $40{ }^{\circ} \mathrm{C}$ to $100^{\circ} \mathrm{C}$ with a volume fraction of $0.05,0.1,0.2,0.4,0.8$ and $1 \mathrm{vol} . \%$ using CuO-MWCN hybrid nanofluids [24]. When the temperature is in all volume fractions of the nanofluids, viscosity decreases exponentially.

\subsection{Shear stress Vs Shear rate}

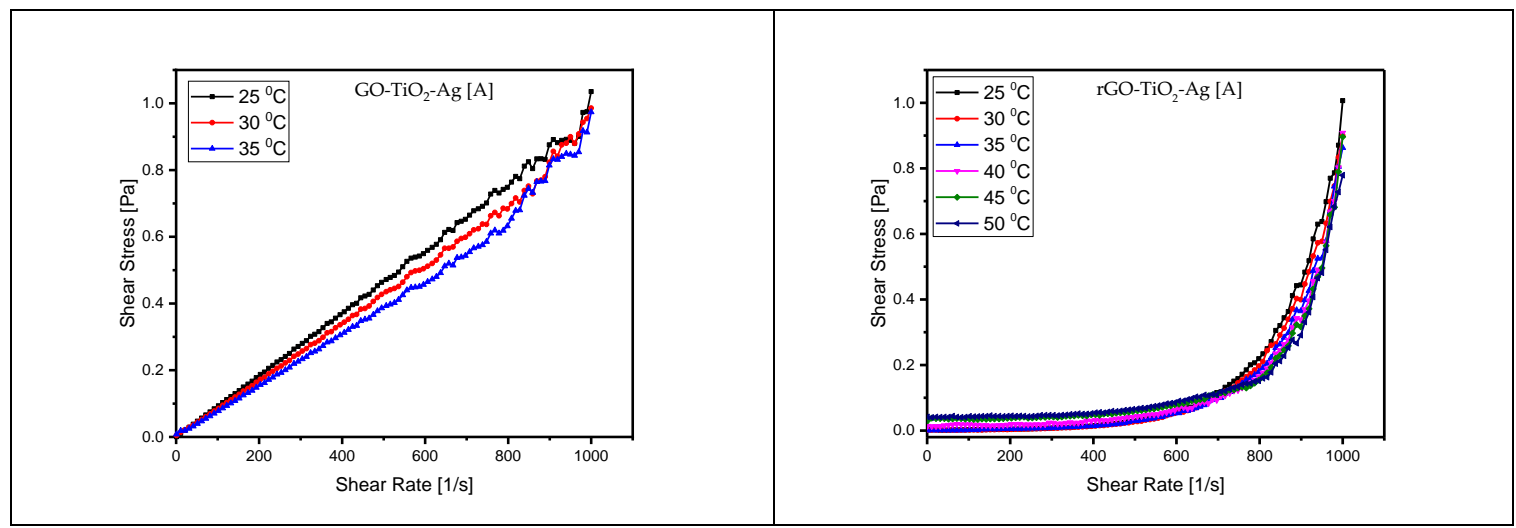




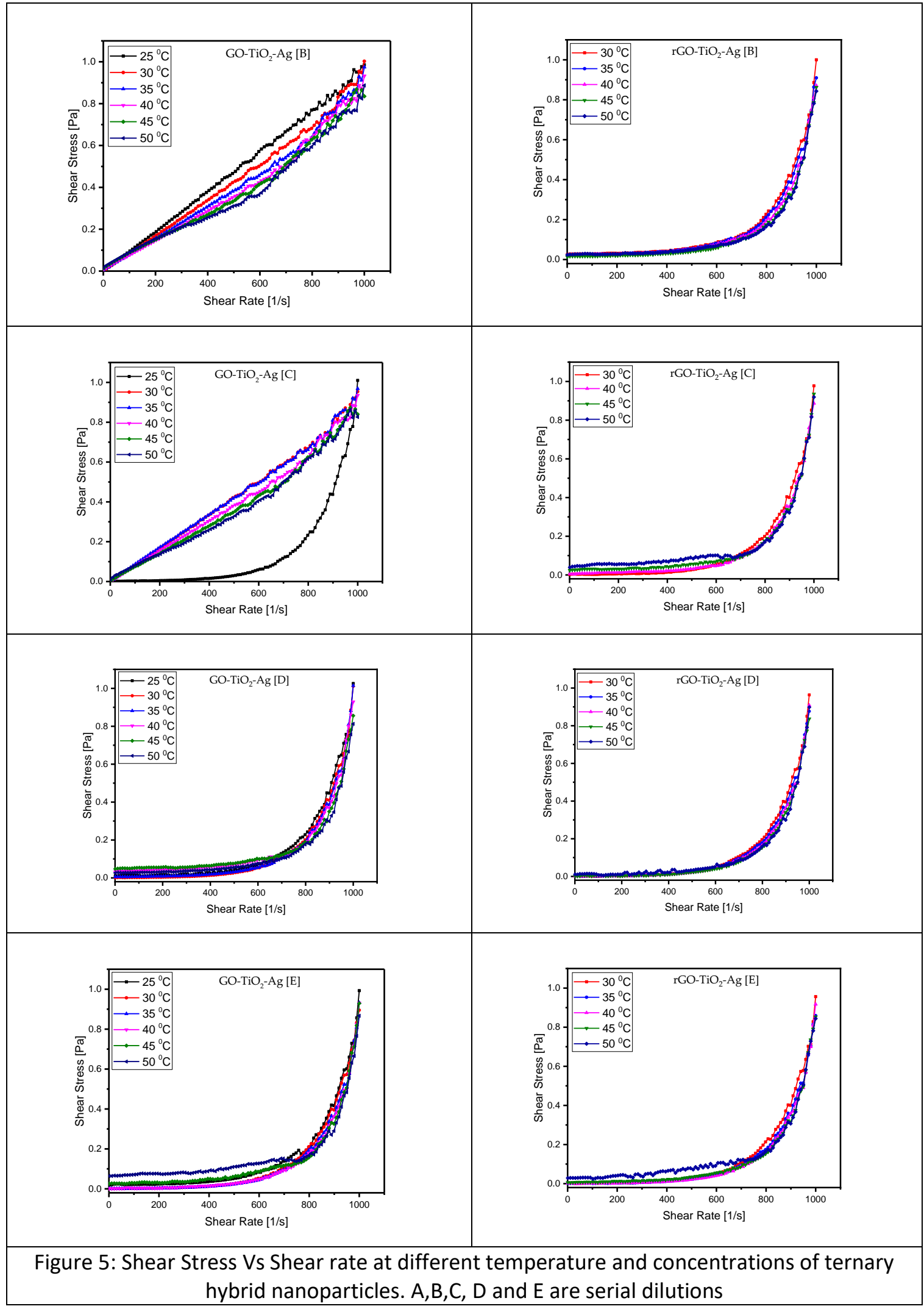

\section{a. Effect of ternary hybrid nanoparticle type on shear rate}

Shear stress is the factor which determines whether the fluid is Newtonian or non-Newtonian. The control of the nanofluid suspension's flow property is crucial in many large scale industries like paint, 
crude oil drilling, handling and transportation, food processing and other consumer health products. The study of their rheological properties will give them an insight to control and for easy transportation of all manufactured products in the above mentioned industries. One of the method to study their flow based property is to determine the shear rate and shear stress of the flow in the fluids. The water based nanofluids generally behave as a shear thinning fluids at temperatures ranging from $30^{\circ} \mathrm{C}$ to $80^{\circ} \mathrm{C}[40]$. Numerous researches have done the study on flow properties from the past few decades and different characteristics were reported like the fluids is Newtonian, nonNewtonian or dilatant or pseudo-plastic or thixotropic fluids etc. The plots in the figure 5 above shows the shear rate versus shear stress for the two types of GO based ternary hybrid nanofluids at various concentrations and temperatures. The GO based ternary hybrid nanofluid behaves as a Newtonian fluid at higher concentration indicating that shear stress is linearly proportional to the shear strain in the fluids at all the measured temperatures. On the other hand the rGO based ternary hybrid nanofluids, the shear stress is not proportional to the shear strain. The GO based ternary hybrid nanofluids even though behave as a Newtonian fluid at higher concentration of nanoparticles gradually behaves as a shear thinning or pseudo-plastic fluid as the concentration is decreased. For instance, it can be seen from the plots that at a particular level of serial dilution (concentration $\mathrm{C}$ ) and at room temperature $\left(25^{\circ} \mathrm{C}\right)$, it behaves like a shear thinning or pseudoplastic fluid while at a higher temperature $\left(30^{\circ} \mathrm{C}\right.$ to $\left.50^{\circ} \mathrm{C}\right)$, it behaves as a Newtonian fluid where the shear stress and shear rate are linearly proportional. The response seen in the concentration $\mathrm{C}$ is known as thixotrophy which is the structural breakdown of bonds between the molecules with the increase of shear rate. The nanofluid behaves like a thixotrophic fluid at a particular concentration and temperature when the shearing forces is more higher and the binding forces or the binding energy is not enough for the solid-liquid layer to retain its structure. It can also be depicted as the breaking or dispersion of the agglomerated particles.

\section{b. Effect of ternary hybrid nanoparticle type on concentration}

The shear stress and shear strain are a function of concentration and temperature. Studies has revealed that the water based nanofluids behave as a Newtonian fluid at lower concentration of nanoparticles in the fluid [41] and as a non-Newtonian fluid at higher concentration. The nanofluids behave as a shear thinning fluids when the concentration of the nanoparticles increased [41]. The plots in the figure 5 shows the various shear stress versus shear strain at different temperatures. A side by side comparison between the $\mathrm{GO}$ and $\mathrm{rGO}$ based ternary hybrid nanofluids are made. The GO based ternary hybrid nanofluid behaves like a Newtonian fluid for the sample $A$ at temperatures ranging from $25^{\circ} \mathrm{C}$ to $50^{\circ} \mathrm{C}$, while the $\mathrm{rGO}$ based Ternary hybrid nanofluids behave like a shear thinning or plastic fluids for the same concentration for all temperatures. In the next plot for the second concentration (sample B), the GO based Ternary hybrid nanofluids at lower temperatures of $25^{\circ} \mathrm{C}$, they behave like a Newtonian fluid but starts to show slight shear thinning behaviour once the temperature is increased till the maximum measured temperature of $50^{\circ} \mathrm{C}$. While rGO based Ternary hybrid nanofluids behaves as a shear thinning fluid from the starting range of $25^{\circ} \mathrm{C}$ till $50^{\circ} \mathrm{C}$. the measurements on concentration (sample C), the GO based Ternary hybrid nanofluids at $25^{\circ} \mathrm{C}$ behaves like a shear thinning fluid but tends to be a Newtonian fluid once the temperature is increased from $30^{\circ} \mathrm{C}$ until the final measured temperature of $50^{\circ} \mathrm{C}$. The concentrations (sample $\mathrm{D}$ and $\mathrm{E}$ ), the Go based Ternary hybrid nanofluids behaves like a shear thinning fluid at all measured temperatures ranging from $25^{\circ} \mathrm{C}$ till $50^{\circ} \mathrm{C}$, while the $\mathrm{rGO}$ based nanofluids follows the same trend and behaves like a shear thinning fluids at all measured temperatures and concentrations. There can be many reasons behind the nanofluids behaviour as Newtonian fluids at higher concentration and as a pseudo-plastic behaviour at lower concentrations. The particle to particle interactions at higher concentrations is stronger and hence it retains as a Newtonian fluid. Once the shear rate and temperature are increased, the particle to particle interactions becomes weaker and the attractive forces diminishes forcing the nanofluids to behave as a pseudo-plastic fluid. On further reduction of 
concentration, the GO based ternary hybrid nanofluids completely behaves as dilatant or shear thickening fluid. This influence of concentration of the nanoparticles in the fluid may be due to the higher inter-particle forces in higher concentration. This higher inter-particle forces influences the nanofluids to remain Newtonian [42]. Whereas the rGO based nanofluids remain consistently as a shear thickening or dilatant fluids in all concentrations and temperatures. This may be due to the lesser number of oxygen molecules in the rGO nanoparticles. Previous rheological studies on hybrid nanofluids have reported that higher volume fraction of nanoparticles trigger the formation of larger nano-clusters which increases the viscosity due to van der Waals forces existing between particles caused by the reduction of movements between fluid layers [43], but from the figure 5, it can be noticed that with the increase in shear rate, the shear stresses decrease gradually, which indicate the weakening of the attraction forces between the fluid layer leading to shear thinning behaviour. The increase in hydrodynamic diameter of the nanoparticle results in adsorption and clustering/agglomeration which tends to increase the viscosity as observed in previous studies[21]. Agglomeration structures formed in the nanofluids during the shearing process gets diminished to an orderly arrangement within the range of shear rate as has been observed by recent researches [21]. Studies by yang et al on $\mathrm{Al}_{2} \mathrm{O}_{3}$-diamond hybrid on $\mathrm{DI}$ water and silicone oil showed that the nanofluids tends to be Newtonian but due to agglomeration but once the shear rate is increased it tends to be non-Newtonian shear thinning fluids similar to the behaviour of the Go based nanofluids in our study. It is also because of the agglomeration due to dominance of van der walls forces at lower shear rates and at higher shear rates, the agglomeration breaks down leading to reduction of viscosity substantially making the fluid to behave as a non-Newtonian shear thinning fluid.

\section{c. Effect of ternary hybrid nanoparticle type on temperature}

Nanofluids at lower shear rates exhibit Newtonian behaviour and non-Newtonian behaviour at higher shear rates as seen from the plots above. Many studies have shown that the temperature is directly related to the change in the rheological properties and as well as thermal conductivity of nanofluids [44]. The rheological measurements on the two GO based ternary hybrid nanofluids were done on temperatures ranging from $25^{\circ} \mathrm{C}$ to $50^{\circ} \mathrm{C}$. It can be seen that the shear stress increases with the increase in shear rate and decreases with temperature. The trend in the GO plots shows that at a particular concentration (sample C) and at lower temperature $\left(25^{\circ} \mathrm{C}\right.$ ), the fluid shows dilatant or shear thinning behaviour but when the temperature is increased $\left(30^{\circ} \mathrm{C}\right.$ to $\left.50^{\circ} \mathrm{C}\right)$, the nanofluid exhibits Newtonian behaviour. On further dilution at a concentration $\mathrm{D}$, the nanofluids completely exhibits shear thinning or pseudo plastic behaviour irrespective of the temperature. The rGO profiles on the other hand exhibits shear thinning or pseudo plastic behaviour on all concentrations and temperatures.

\section{Comparison of experimental results with viscosity models}

A substantial number of researchers have dwelled into finding the exact cause of the increase of viscosity of hybrid nanofluids. Various studies have developed several correlations for determining the viscosity of hybrid nanoparticles since its inception. Even though they were successful in determining the correlations for the nanofluids, studies till now has not been able to determine a universal correlation for the determination of viscosity in a nanofluids. The correlations derived till now have been different based on the type of nanoparticle used, their type of base fluids, the temperature range, concentration range of nanoparticles, sonication time of nanoparticles in the base fluids, with/without the addition of surfactant, number of nanoparticles in a hybrid nanoparticle combination and its ratio etc. the Experimental results of this study is compared with few of the existing hybrid viscosity models of water based base fluids (Table1) by choosing a single set of temperature $\left(35^{\circ} \mathrm{C}\right)$ as presented in the figure 6 . The comparison indicate that few of the hybrid 
Table 1: Viscosity Models for water and ethylene glycol based hybrid nanofluids

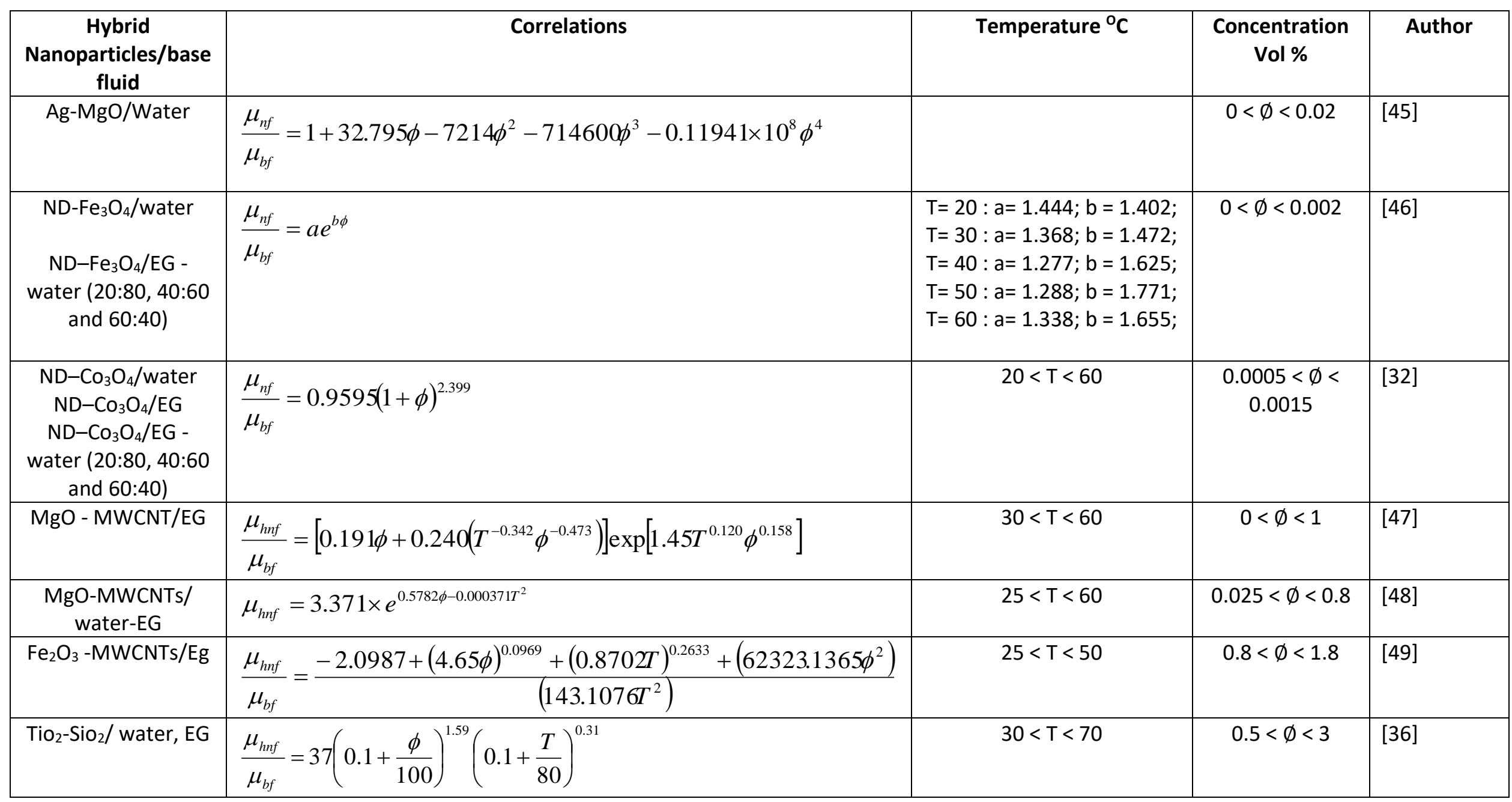




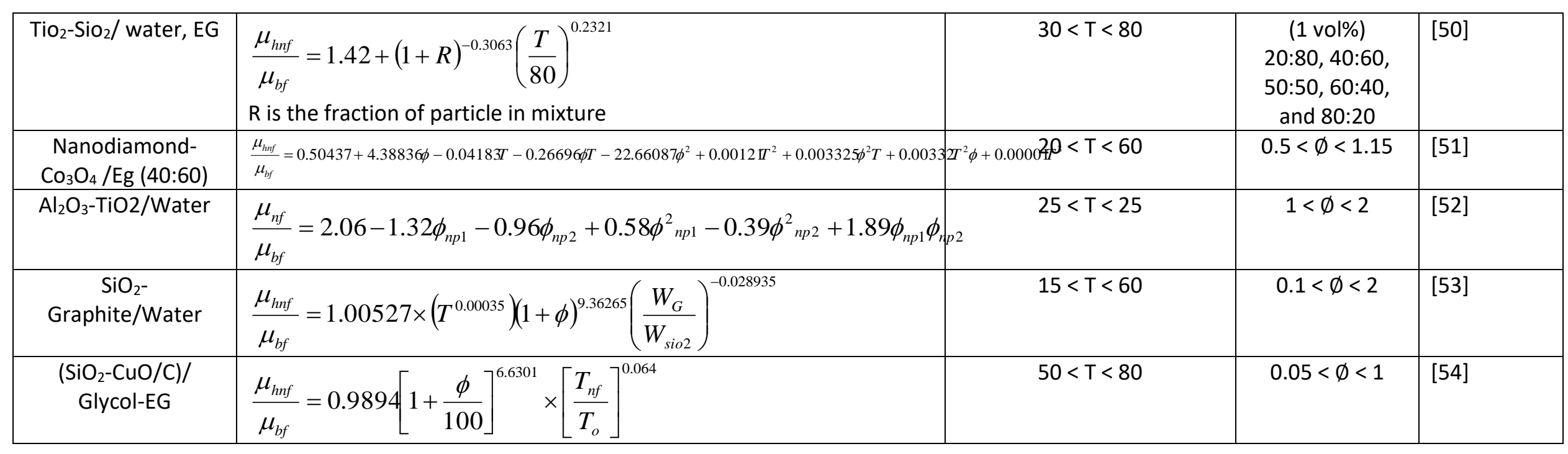


viscosity correlation with the experimental results of the ternary hybrid nanofluids. It can be seen from figure 6 , few of the existing water based hybrid viscosity correlations do agree with the experimental results.

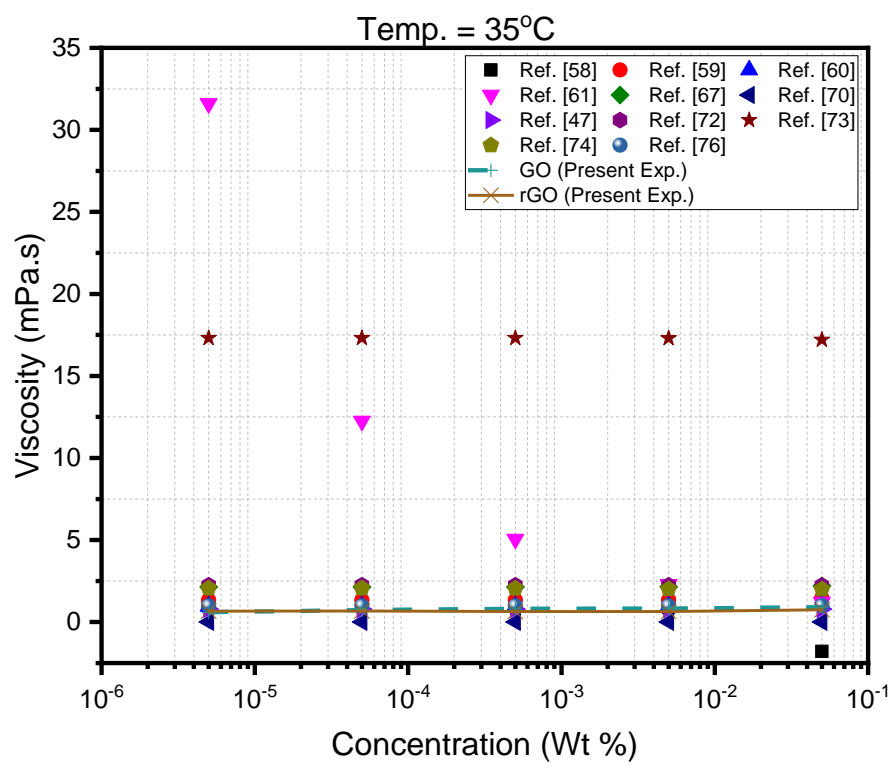

Figure 6: comparison of existing viscosity models with experimental results at $35^{\circ} \mathrm{C}$

\subsection{Amplitude sweep}

The linear viscoelastic (LVE) is a region which indicates the range in the fluid in which the stresses are tested without destroying the fluid structure. The LVE measurements are another set of rheological measurements which can be determined by measuring stresses which can be divided into storage (G'- elastic) and loss (G" - viscous) moduli. The loss and storage moduli shows the mechanical properties of the nanoparticles under low oscillatory shear. It is the range with the lowest strain values. The $\mathrm{G}^{\prime}$ in the LVE region shows a constant value which is also called the plateau value. These measurements are done using the rheometer in which in the spindle performs oscillatory motions of stress range between 0.01 and $10 \mathrm{~Pa}$ at a constant frequency of $1 \mathrm{~Hz}$. if $\mathrm{G}^{\prime \prime}>\mathrm{G}^{\prime}$, then the fluid can be termed a viscoelastic liquid. When an external strain is applied on the fluids, the fluids structure opposes the strains until a certain extent where the loss modulus $G^{\prime}$ increases. Then the fluid structure in the LVE deforms leading to dismantling of the aggregations of the nanoparticles in the fluid. This will lead to nanoparticles in the fluids align to the flow field which in turn decreases the storage and loss moduli in the fluid. The plots in figure 6 shows the loss and storage moduli of the two GO based ternary hybrid nanofluids. It can be seen that the curves demonstrate a similar qualitative feature with sharp decline of high oscillating stresses and characterized by constant modulus or linear viscoelastic plateau. It can also be seen from the plots that the loss modulus are higher in the nanofluids with higher concentrations. There is a crossover area between the loss and storage moduli which shows the presence of yield stress in the nanofluids as mentioned by few studies. At higher shear strain, the G' decreases indicating the loss of viscoelastic structure in the nanofluid. One striking feature is that at lower concentrations both GO and rGO based ternary hybrid nanofliuds, the loss modulus is almost similar indicating the nanofluids losses the ability to loss or store stresses and remains constant at all measured temperatures. This indicates that it is the nanoparticles in the fluids enhances the rheological abilities like storage, damping and loss moduli in 
the fluids. This maybe one of the reason for enhancement of thermal conductivity and other rheological properties. Network structures are formed in the nanofluids at higher particle concentrations at lower stresses or frequencies as reported by some studies[39]. It is noted from the plots that the critical external strain is independent of all concentrations of the fluids. It should be noted that the base fluids exhibit a Newtonian behaviour but with the addition of ternary hybrid nanoparticles in the base fluids transitions it to viscoelastic behaviour which is shear thinning or pseudo plastic behaviour in our case and dilatant in other cases. The damping factor is a dimensionless unit which can be described as the ratio of loss over storage moduli $\left(G^{\prime \prime} / G^{\prime}\right)$ which is denoted by the term tan $\delta$. The ideal value for the damping factor for a liquid in viscoelastic region is always greater than unity $\left(\tan \delta=G^{\prime \prime} / G^{\prime}>1\right)$. The damping factor plots are shown in the figure insets in each plots.

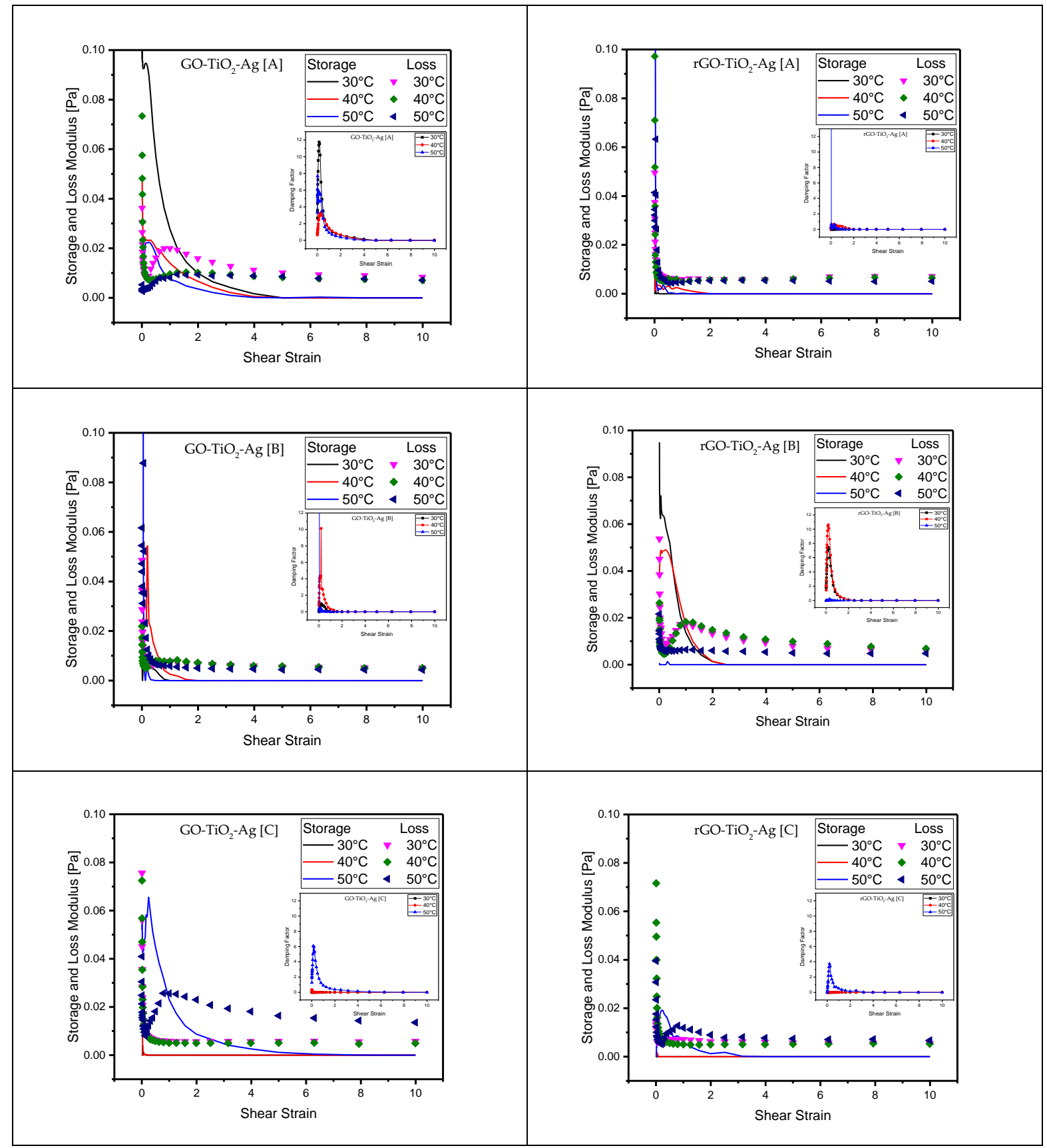




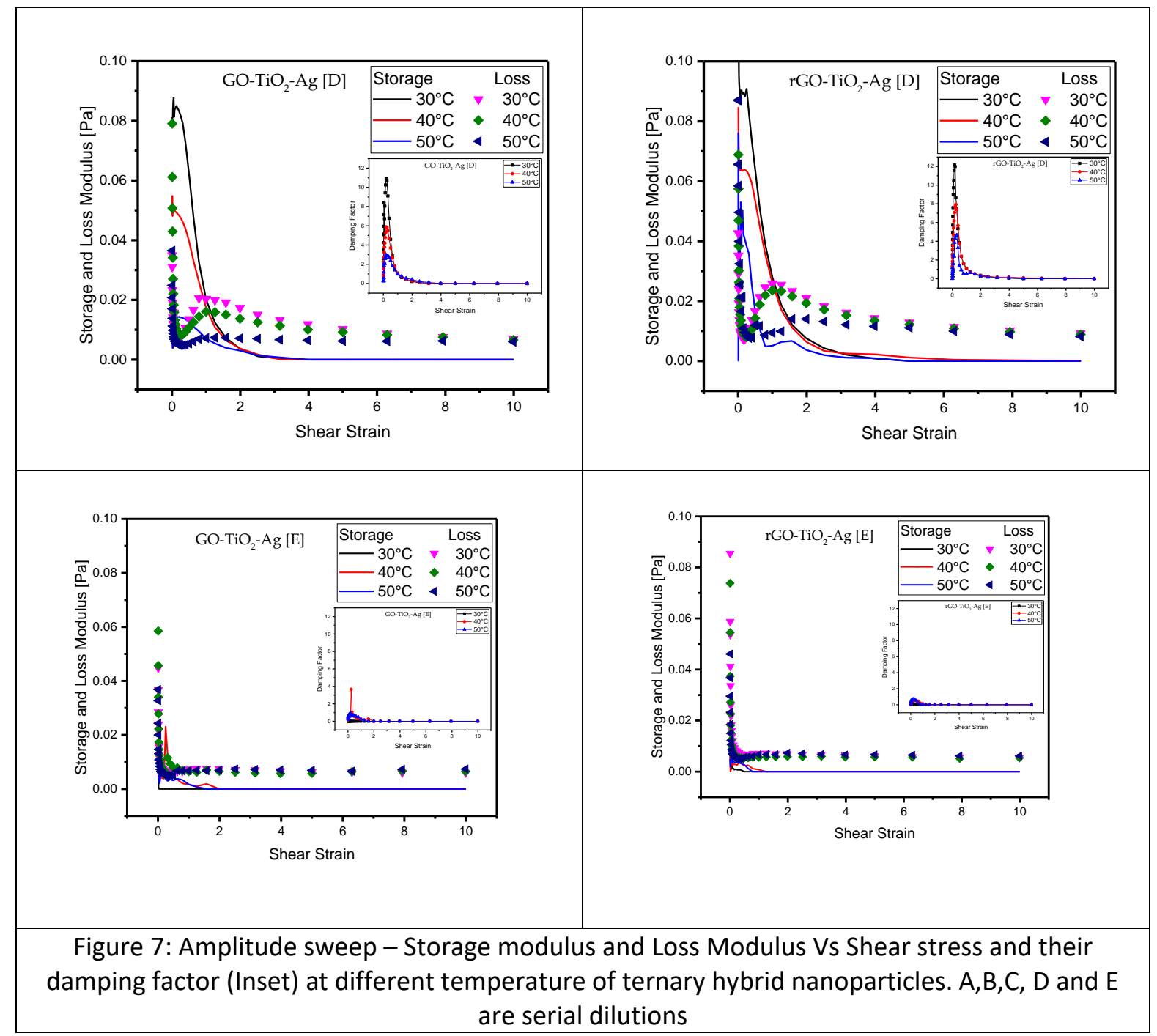

\subsection{Frequency sweep}

Frequency sweep tests are carried out to measure the time-dependant behaviour of the nanofluids in a non-destructive deformation range. It is an important tool to measure the stability of the nanofluids. It helps to quantify zero shear viscosity for viscoelastic liquids. Frequency sweeps can be measured either by using fast moving high frequency simulation or by slow moving low frequency simulation. The frequency sweeps were measured in the LVE region with angular frequencies ranging from frequency range of $0.1 \mathrm{~Hz}$ to $10 \mathrm{~Hz}(0.628 \mathrm{rad} / \mathrm{s}$ to $62.831 \mathrm{rad} / \mathrm{s})$ by applying oscillatory stress of $0.05 \mathrm{~Pa}$. The loss and storage moduli are similar and practically constant in all the concentrations of the measured ternary hybrid nanofluids. The measurements show that at higher frequencies both the storage and the loss moduli increases. Damping factor is shown in the figure insets. It can be seen that the damping factors are higher only in the viscoelastic region with low angular frequency. Once the frequency is increased, the damping factor is minimum and are also uniform across all the concentrations and also independent of temperature. Both the GO and rGO based ternary hybrid nanofluids exhibit a similar trend for the damping factor. The damping factor decreases exponentially with the increase in angular frequency. 


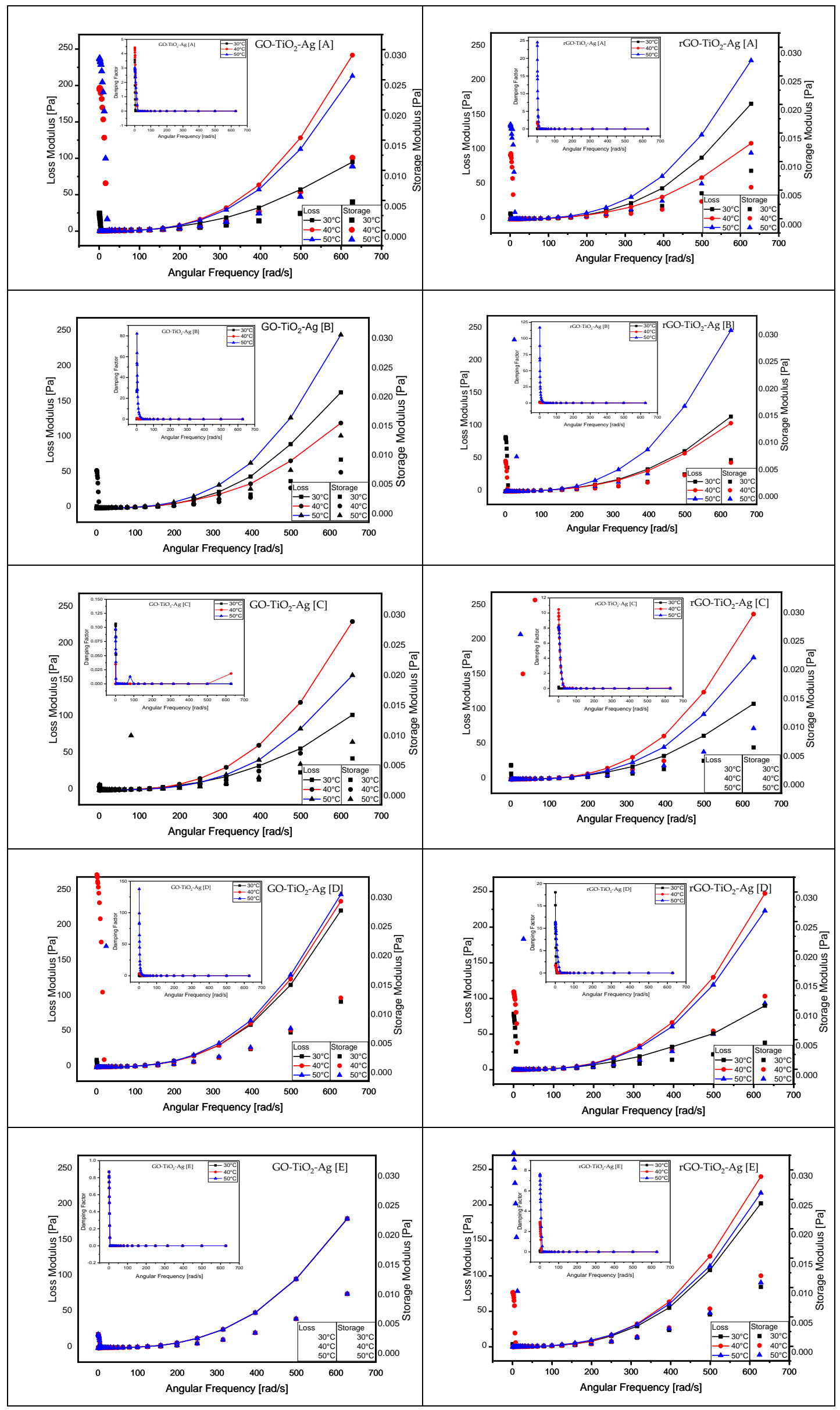


Figure 8: Frequency sweep - Storage modulus and Loss Modulus Vs Shear stress and their damping factor (Inset) at different temperature of ternary hybrid nanoparticles. A,B,C, D and E are serial dilutions

\section{Conclusion}

Two different ternary hybrid nanoparticles $\left(\mathrm{GO}-\mathrm{TiO}_{2}-\mathrm{Ag}\right.$ and $\left.\mathrm{rGO}^{-} \mathrm{TiO}_{2}-\mathrm{Ag}\right)$ were synthesised and dispersed in double distilled deionised water with a concentration of $0.05 \%$ wt. The nanofluids are then serially diluted to five levels. The stability of the concentrated stock solution is checked by measuring the Zeta potential. It showed that the measured value was in a range between $25 \mathrm{mV}$ to $5 \mathrm{mV}$ which are considered to be stable. Anton-Paar MCR302 modular compact rheometer was used for rheological measurements. The measurements were carried out in controlled stress and temperature with the temperatures ranging from $25^{\circ} \mathrm{C}$ to $50^{\circ} \mathrm{C}$ at $5^{\circ} \mathrm{C}$ increments.

The following conclusions were obtained;

1. The GO based ternary hybrid nanofluids were observed to exhibit Newtonian behaviour with higher concentrations whereas the nanofluids exhibits as non-Newtonian shear thinning behaviour or Pseudo-plastic at lower concentrations.

2. The ternary hybrid nanofluids behaves like Newtonian fluids at lower temperatures. At higher temperatures and lower shear rates, the viscosity decreases indicating Shear thinning behaviour. Phase separation is believed to be the reason for the nanofluid's shear thinning behaviour.

3. The viscosity of GO and rGO based THN fluids behaves opposite to each other. The viscosity of $\mathrm{GO}$ based nanofluid increases while the viscosity of $\mathrm{rGO}$ based nanofluid decrease with the decrease of concentration of nanoparticles in the fluid.

4. Concentration plays a vital role in the change of viscosity with the change in temperature. Van der Waals forces acts on the particles in lower temperatures whereas at higher temperatures there is very weak force of attraction leading to decrease in viscosity. Agglomeration plays a crucial at higher temperatures.

5. The GO based nanofluid behaves as a Newtonian fluid at higher concentrations while the rGO behaves as a dilatant fluid or shear thickening. The GO based nanofluids at lower concentrations follows the similar trends as $\mathrm{rGO}$ based Ternary hybrid nanofluids.

6. The effects of concentration, temperature and stresses applied on the non-linear viscoelastic reveals the presence of linear viscoelastic (LVE) region. Non-destructive stress tests were conducted using oscillating angular sweep test and frequency sweep tests.

7. Nanofluids exhibit higher loss modulus at higher concentrations. The loss or damping factor ratio plots revealed that the loss factor is higher only in the viscoelastic region with low angular frequency whereas it is minimum and constant at higher angular frequencies irrespective of temperatures.

\section{Acknowledgments}

The Authors are grateful to Sunway university's Graphene and Advanced 2D Materials Research Group for helping us with the equipment and measurements.

\section{References:}

[1] S. Chakraborty and P. K. Panigrahi, "Stability of nanofluid: A review," Appl. Therm. Eng., vol. 174, no. December 2019, 2020.

[2] L. Yang, W. Ji, M. Mao, and J. nan Huang, "An updated review on the properties, fabrication 
and application of hybrid-nanofluids along with their environmental effects," J. Clean. Prod., vol. 257, p. $120408,2020$.

[3] H. Babar, M. Sajid, and H. Ali, "Viscosity of hybrid nanofluids: A critical review," Therm. Sci., vol. 23, no. 3 Part B, pp. 1713-1754, 2019.

[4] A. K. Rasheed, M. Khalid, W. Rashmi, T. C. S. M. Gupta, and A. Chan, "Graphene based nanofluids and nanolubricants - Review of recent developments," Renew. Sustain. Energy Rev., vol. 63, no. September, pp. 346-362, 2016.

[5] K. S. Mekheimer, W. M. Hasona, R. E. Abo-Elkhair, and A. Z. Zaher, "Peristaltic blood flow with gold nanoparticles as a third grade nanofluid in catheter: Application of cancer therapy," Phys. Lett. Sect. A Gen. At. Solid State Phys., vol. 382, no. 2-3, pp. 85-93, 2018.

[6] H. Babar and H. M. Ali, "Towards hybrid nanofluids: Preparation, thermophysical properties, applications, and challenges," J. Mol. Liq., vol. 281, pp. 598-633, 2019.

[7] A. Khaliq R, R. Kafafy, H. M. Salleh, and W. F. Faris, "Enhancing the efficiency of polymerase chain reaction using graphene nanoflakes," Nanotechnology, vol. 23, no. 45, p. 455106, Nov. 2012.

[8] R. Abdul Khaliq et al., "Enhancement in the efficiency of polymerase chain reaction by TiO2 nanoparticles: crucial role of enhanced thermal conductivity.," Nanotechnology, vol. 21, no. 25, p. 255704, 2010.

[9] D. Sharma, K. M. Pandey, A. Debbarma, and G. Choubey, "Numerical Investigation of heat transfer enhancement of SiO2-water based nanofluids in Light water nuclear reactor," Mater. Today Proc., vol. 4, no. 9, pp. 10118-10122, 2017.

[10] I. Zakaria, W. H. Azmi, W. A. N. W. Mohamed, R. Mamat, and G. Najafi, “Experimental Investigation of Thermal Conductivity and Electrical Conductivity of Al2O3 Nanofluid in Water - Ethylene Glycol Mixture for Proton Exchange Membrane Fuel Cell Application," Int. Commun. Heat Mass Transf., vol. 61, pp. 61-68, 2015.

[11] N. A. Che Sidik, M. Mahmud Jamil, W. M. A. Aziz Japar, and I. Muhammad Adamu, "A review on preparation methods, stability and applications of hybrid nanofluids," Renew. Sustain. Energy Rev., vol. 80, no. January 2016, pp. 1112-1122, 2017.

[12] E. Bhatia and R. Banerjee, "Hybrid silver-gold nanoparticles suppress drug resistant polymicrobial biofilm formation and intracellular infection," J. Mater. Chem. B, vol. 8, no. 22, pp. 4890-4898, 2020.

[13] S. D. Perera et al., "Hydrothermal synthesis of graphene-TiO 2 nanotube composites with enhanced photocatalytic activity," ACS Catal., vol. 2, no. 6, pp. 949-956, 2012.

[14] D. K. Devendiran and V. A. Amirtham, "A review on preparation, characterization, properties and applications of nanofluids," Renewable and Sustainable Energy Reviews, vol. 60. pp. 2140, 2016.

[15] A. Arshad, M. Jabbal, Y. Yan, and D. Reay, "A review on graphene based nanofluids: Preparation, characterization and applications," J. Mol. Liq., vol. 279, pp. 444-484, 2019.

[16] W. H. Azmi, K. V. Sharma, R. Mamat, G. Najafi, and M. S. Mohamad, "The enhancement of effective thermal conductivity and effective dynamic viscosity of nanofluids - A review," Renewable and Sustainable Energy Reviews, vol. 53. pp. 1046-1058, 2016.

[17] H. Aybar, M. Sharifpur, M. R. Azizian, M. Mehrabi, and J. P. Meyer, "A review of thermal conductivity models for nanofluids," Heat Transf. Eng., vol. 36, no. 13, pp. 1085-1110, Sep. 
2015.

[18] R. V. Pinto and F. A. S. Fiorelli, "Review of the mechanisms responsible for heat transfer enhancement using nanofluids," Appl. Therm. Eng., vol. 108, pp. 720-739, Sep. 2016.

[19] M. R. Esfahani, E. M. Languri, and M. R. Nunna, "Effect of particle size and viscosity on thermal conductivity enhancement of graphene oxide nanofluid," Int. Commun. Heat Mass Transf., vol. 76, pp. 308-315, 2016.

[20] A. K. Sharma, A. K. Tiwari, and A. R. Dixit, "Rheological behaviour of nanofluids: A review," Renew. Sustain. Energy Rev., vol. 53, pp. 779-791, 2016.

[21] S. M. S. Murshed and P. Estellé, "A state of the art review on viscosity of nanofluids," Renew. Sustain. Energy Rev., vol. 76, no. March, pp. 1134-1152, 2017.

[22] J. P. Meyer, S. A. Adio, M. Sharifpur, and P. N. Nwosu, "The Viscosity of Nanofluids: A Review of the Theoretical, Empirical, and Numerical Models," Heat Transf. Eng., vol. 37, no. 5, pp. 387-421, Mar. 2016.

[23] H. D. Koca, S. Doganay, A. Turgut, I. H. Tavman, R. Saidur, and I. M. Mahbubul, "Effect of particle size on the viscosity of nanofluids: A review," Renew. Sustain. Energy Rev., vol. 82, no. February, pp. 1664-1674, 2018.

[24] M. Hemmat Esfe, F. Zabihi, H. Rostamian, and S. Esfandeh, "Experimental investigation and model development of the non-Newtonian behavior of CUO-MWCNT-10w40 hybrid nanolubricant for lubrication purposes," J. Mol. Liq., vol. 249, pp. 677-687, Jan. 2018.

[25] V. Kumar and J. Sarkar, "Numerical and experimental investigations on heat transfer and pressure drop characteristics of Al 203 -TiO 2 hybrid nanofluid in minichannel heat sink with different mixture ratio," Powder Technology, vol. 345. pp. 717-727, 2019.

[26] F. Amini, S. Z. Miry, A. Karimi, and M. Ashjaee, "Experimental Investigation of Thermal Conductivity and Viscosity of SiO 2 /Multiwalled Carbon Nanotube Hybrid Nanofluids," J. Nanosci. Nanotechnol., vol. 19, no. 6, pp. 3398-3407, Jun. 2019.

[27] A. A. Hussien, M. Z. Abdullah, N. M. Yusop, M. A. Al-Nimr, M. A. Atieh, and M. Mehrali, "Experiment on forced convective heat transfer enhancement using MWCNTs/GNPs hybrid nanofluid and mini-tube," Int. J. Heat Mass Transf., vol. 115, pp. 1121-1131, 2017.

[28] I. M. Mahbubul, Rheological Behavior of Nanofluid. 2019.

[29] I. M. Mahbubul, R. Saidur, and M. A. Amalina, "Latest developments on the viscosity of nanofluids," Int. J. Heat Mass Transf., vol. 55, no. 4, pp. 874-885, 2012.

[30] N. A. C. Sidik, I. M. Adamu, M. M. Jamil, G. H. R. Kefayati, R. Mamat, and G. Najafi, "Recent progress on hybrid nanofluids in heat transfer applications: A comprehensive review," International Communications in Heat and Mass Transfer, vol. 78. pp. 68-79, 2016.

[31] M. H. Hamzah, N. A. C. Sidik, T. L. Ken, R. Mamat, and G. Najafi, "Factors affecting the performance of hybrid nanofluids: A comprehensive review," Int. J. Heat Mass Transf., vol. 115, pp. 630-646, 2017.

[32] L. S. Sundar, G. O. Irurueta, E. Venkata Ramana, M. K. Singh, and A. C. M. Sousa, "Thermal conductivity and viscosity of hybrid nanfluids prepared with magnetic nanodiamond-cobalt oxide (ND-Co304) nanocomposite," Case Stud. Therm. Eng., vol. 7, pp. 66-77, Mar. 2016.

[33] J. A. Ranga Babu, K. K. Kumar, and S. Srinivasa Rao, "State-of-art review on hybrid nanofluids," Renew. Sustain. Energy Rev., vol. 77, no. March, pp. 551-565, 2017. 
[34] B. Wang, X. Wang, W. Lou, and J. Hao, "Thermal conductivity and rheological properties of graphite/oil nanofluids," Colloids Surfaces A Physicochem. Eng. Asp., vol. 414, pp. 125-131, 2012.

[35] M. S. Kumar, V. Vasu, and A. V. Gopal, "Thermal conductivity and rheological studies for CuZn hybrid nanofluids with various basefluids," J. Taiwan Inst. Chem. Eng., vol. 66, pp. 321327, Sep. 2016.

[36] M. F. Nabil, W. H. Azmi, K. Abdul Hamid, R. Mamat, and F. Y. Hagos, "An experimental study on the thermal conductivity and dynamic viscosity of TiO2-SiO2 nanofluids in water: Ethylene glycol mixture," Int. Commun. Heat Mass Transf., vol. 86, pp. 181-189, 2017.

[37] X. Hu, D. Yin, J. Xie, X. Chen, and C. Bai, "Experimental study of viscosity characteristics of graphite/engine oil (5 W-40) nanofluids," Appl. Nanosci., vol. 10, no. 6, pp. 1743-1756, 2020.

[38] N. Ali, J. A. Teixeira, and A. Addali, "A Review on Nanofluids: Fabrication, Stability, and Thermophysical Properties," J. Nanomater., vol. 2018, 2018.

[39] S. N. A. Shah et al., "Experimental investigation on stability, thermal conductivity and rheological properties of rGO/ethylene glycol based nanofluids," Int. J. Heat Mass Transf., vol. 150, p. 118981, 2020.

[40] H. Yang, G. Yao, and D. Wen, "Experimental investigation on convective heat transfer of Shear-thinning fluids by elastic turbulence in a serpentine channel," Exp. Therm. Fluid Sci., vol. 112, p. 109997, Apr. 2020.

[41] S. Halelfadl, P. Estellé, B. Aladag, N. Doner, and T. Maré, "Viscosity of carbon nanotubes water-based nanofluids: Influence of concentration and temperature," Int. J. Therm. Sci., vol. 71, pp. 111-117, Sep. 2013.

[42] A. Kaggwa and J. K. Carson, "Developments and future insights of using nanofluids for heat transfer enhancements in thermal systems: a review of recent literature," Int. Nano Lett., vol. 9, no. 4, pp. 277-288, 2019.

[43] M. Afrand, K. Nazari Najafabadi, and M. Akbari, "Effects of temperature and solid volume fraction on viscosity of SiO2-MWCNTs/SAE40 hybrid nanofluid as a coolant and lubricant in heat engines," Appl. Therm. Eng., vol. 102, pp. 45-54, 2016.

[44] G. Colangelo, E. Favale, P. Miglietta, M. Milanese, and A. de Risi, "Thermal conductivity, viscosity and stability of Al2O3-diathermic oil nanofluids for solar energy systems," Energy, vol. 95, pp. 124-136, 2016.

[45] M. Hemmat Esfe, A. A. Abbasian Arani, M. Rezaie, W. M. Yan, and A. Karimipour, "Experimental determination of thermal conductivity and dynamic viscosity of AgMgO/water hybrid nanofluid," Int. Commun. Heat Mass Transf., vol. 66, pp. 189-195, 2015.

[46] L. S. Sundar, M. K. Singh, and A. C. M. Sousa, "Experimental thermal conductivity and viscosity of nanodiamond-based propylene glycol and water mixtures," Diamond and Related Materials, vol. 69. pp. 49-60, 2016.

[47] O. Soltani and M. Akbari, "Effects of temperature and particles concentration on the dynamic viscosity of MgO-MWCNT/ethylene glycol hybrid nanofluid: Experimental study," Phys. E Low-Dimensional Syst. Nanostructures, vol. 84, pp. 564-570, 2016.

[48] A. Zareie and M. Akbari, "Hybrid nanoparticles effects on rheological behavior of water-EG coolant under different temperatures: An experimental study," J. Mol. Liq., vol. 230, pp. 
408-414, Mar. 2017.

[49] A. Ahmadi Nadooshan, H. Eshgarf, and M. Afrand, "Measuring the viscosity of Fe304MWCNTs/EG hybrid nanofluid for evaluation of thermal efficiency: Newtonian and nonNewtonian behavior," J. Mol. Liq., vol. 253, pp. 169-177, Mar. 2018.

[50] K. A. Hamid, W. H. Azmi, M. F. Nabil, R. Mamat, and K. V. Sharma, "Experimental investigation of thermal conductivity and dynamic viscosity on nanoparticle mixture ratios of TiO2-SiO2 nanofluids," International Journal of Heat and Mass Transfer, vol. 116. pp. 1143-1152, 2018.

[51] M. Hemmat Esfe and M. H. Hajmohammad, "Thermal conductivity and viscosity optimization of nanodiamond-Co3O4/EG (40:60) aqueous nanofluid using NSGA-II coupled with RSM," J. Mol. Liq., vol. 238, pp. 545-552, Jul. 2017.

[52] G. M. Moldoveanu, A. A. Minea, M. lacob, C. Ibanescu, and M. Danu, "Experimental study on viscosity of stabilized Al2O3, TiO2 nanofluids and their hybrid," Thermochim. Acta, vol. 659, no. June 2017, pp. 203-212, 2018.

[53] A. S. Dalkılıç et al., "Experimental investigation on the viscosity characteristics of water based SiO2-graphite hybrid nanofluids," Int. Commun. Heat Mass Transf., vol. 97, pp. 30-38, 2018.

[54] S. Akilu, A. T. Baheta, M. A. Mior, A. A. Minea, and K. V. Sharma, "Properties of glycerol and ethylene glycol mixture based $\mathrm{SiO}-\mathrm{CuO} / \mathrm{C}$ hybrid nanofluid for enhanced solar energy transport," Sol. Energy Mater. Sol. Cells, vol. 179, pp. 118-128, Jun. 2018. 